\title{
La mujer anarquista. Discursos en torno a la construcción de sujeto femenino revolucionario en los albores de la "idea"*
}

\author{
Anarchist woman. Discourse around the construction of a female revolutionary \\ subject in the beginnings of The Idea
}

\author{
Adriana Palomera Valenzuela ${ }^{* *}$
}

\begin{abstract}
Resumen
En la actualidad la búsqueda de igualdad entre mujeres y hombres se ha convertido en uno de los desafíos de una parte significativa de la sociedad. Para lograr este reto, desde las ciencias sociales y en particular desde la historia, se inició la búsqueda en el pasado de la participación femenina en ámbitos que, hasta ahora, habían sido preferentemente explorados para rescatar a los varones, sus virtudes y aportes. Lejos de la pluma académica quedaron aspectos fundamentales de la condición de la mujer como la construcción del sujeto femenino. En esta búsqueda, este artículo examina la construcción de sujeto femenino anarquista desde el análisis de la tribuna teórica de los clásicos libertarios y a partir de artículos de prensa anarquista de Chile y Argentina de los albores del Siglo XX, con el fin de reconocer el aporte de los ácratas a la construcción política y social de las mujeres del período.
\end{abstract}

Palabras Claves: Sujetos, femenino, mujeres, anarquismo, subjetividades

\begin{abstract}
Nowadays the search of equality between women and men has been converted into the main challenges of a significant part of society. To fulfill this challenge, from the social sciences and, in particular, from the History discipline, it has begun a search in the past of the female participation in fields that, until now, have been principally explored to rescue the men, their virtues and gains. Some fundamental features of women condition in the construction of a female subject, have been let far from the academic research. Inside this search, this article studies the construction of a female anarchist subject from the analysis of the theorist tribune of the libertarian principal writings and from newspapers from Chile and Argentina in the beginning of Twenty Century. Pointing to realize the output of "acratas" in the political and social construction of the women in that period.
\end{abstract}

Keywords: Subjects, women, female, anarchists, subjectivities

\footnotetext{
* Este artículo es parte de la investigación de Tesis doctoral. Becaria CONICYT

** Chilena, Doctora en Estudios Americanos Chilena, Universidad de Santiago de Chile. Docente en la Universidad Arcis
} 


\section{Introducción}

La constitución y naturaleza de los sujetos políticos y sociales, se ha convertido en las últimas décadas en uno de los objetos de estudio que ha congregado a una diversidad de intelectuales de distintas disciplinas. Desde lo particular, uno de los desafíos académicos ha sido la construcción del imaginario del o de los sujetos femeninos.

Las primeras investigaciones sobre las mujeres, resaltaron preferentemente su relación con el plano doméstico. Respondiendo a la posición social modernizadora que habían adquirido luego de su significativa participación en los procesos emancipadores de Europa, Norteamérica y América Latina del siglo XVIII y XIX, las mujeres, especialmente las representantes de elite burguesa, comenzaron a ser desvinculadas de los espacios públicos, siendo recluidas a la esfera privada. Para ellas, la libertad, igualdad y fraternidad se convirtió en una quimera, frente a la cual consciente o inconscientemente hicieron resistencia. Esta particularidad, determinó que se construyera un imaginario de mujer que lejos de representar a la mayoría de ellas, terminó por ser un eslabón de la invisibilidad de las féminas en su integralidad. En este sentido, aparecieron relatos desde los distintos ámbitos del poder como la iglesia y los sectores conservadores y posteriormente incluso, desde los más progresistas, que bajo estos enfoques construyeron un sujeto femenino, que salvo excepciones, se presentó “inerte”, “acompañante” y sufriente.

Pasaron años para que este imaginario avanzara hacia otras construcciones, las primeras de este tipo recompusieron su vínculo con los ámbitos del poder, cualquiera fuera este. De esta forma, las corrientes feministas y sufragistas, por mucho tiempo, reivindicaron a la mujer ideal, aquella que luchó por la participación política o bien a aquellas que lograron, no sin esfuerzo, tener estudios y profesión. Sin embargo mayoritariamente la representación generada operó sobre un sujeto necesario a ese esquema de emancipación de género o de participación electoral en general. Obviando en aquellas referencias sintetizadoras aunque parciales, las diferencias de clase, actividad económica, marginación cultural o condición étnica. ¿Era lo mismo ser blanca que india o mestiza? La noción de mujer subsumió la especificidad del ser mujer en cada caso específico y operó en el sentido de un indeseado e involuntario ocultamiento tras el reconocimiento merecido de las más ilustradas, más visibles y más notables.

Las mujeres fueron prácticamente invisibilizadas por la historia tradicional, o en el mejor de los casos, cuando se prodigaba una mirada hacia ellas, ésta estaba enmarcada en la construcción de una representación de un tipo de mujer (la mujer del patriciado) que pertenecía a los sectores dominantes de la sociedad chilena en los distintos momentos de nuestra historia, o bien por la tendencia a caracterizar a las mujeres populares de manera superficial y estereotipada, generalmente denostándola u otorgándole una mínima presencia en la sociedad chilena en general y decimonónica en particular.

Por su parte la historiografía marxista clásica, centrada en aspectos estructurales o en aspectos políticos formales, sin duda relevantes, como las grandes organizaciones y episodios de lucha, las mujeres eran siempre, las compañeras; aquellas que al igual que los hombres pertenecían al mundo obrero entendido generalmente como una clase perfectamente estructurada, homogénea y con conciencia de clase. En este rango de categorización de naturaleza estructural, el obrero - 
entendido como un sujeto necesario- era sólo uno e indiviso, por lo tanto no era necesaria su identificación particular, sus pliegues subjetivos, sus entramados particulares diferenciadores o sus diferencias de género. Ahora bien, fueron esas mujeres trabajadoras, proletarias o asalariadas en general pero llenas de subjetividad y riqueza cultural, las que por lo general se perdieron en este amplio y aglutinador discurso clásico de emancipación. Esta corriente dio la mayor importancia al estudio del movimiento obrero, sus líderes, contradicciones de clase, condiciones materiales de la explotación, partidos políticos y alianzas entre otros.

Lentamente, junto a este enfoque se produjo en las últimas décadas un acercamiento a la historia e historicidad de otras mujeres, de aquellas populares, las trabajadoras, las militantes, las marginales. Esto probablemente ligado a la urgencia a nivel mundial por lograr avanzar en prácticas igualitarias entre mujeres y hombres, y por la permanente necesidad de visualizar las identidades y subjetividades construidas en torno a ellas. Se debe mencionarse en esta línea a historiadoras como Alejandra Brito, Carola Agliati, Lorena Godoy, Claudia Montero, Julia Antivilo, entre otras autoras que han incursionado en el estudio de las mujeres. Estas han reconstruido la historicidad de la mujer aportando desde distintos enfoques a la visibilización de las mujeres. ${ }^{1}$

Para el caso argentino, existen variados trabajos sobre el tema, destacando la recopilación de Dora Barrancos, una de las primeras investigadoras que se acercó al tema de la mujer y del anarquismo argentino con la publicación del libro "Anarquismo, Educación y costumbres en la Argentina de principios de siglo" ${ }^{2}$. También es relevante mencionar a las autoras argentinas Claudia Bacci, Laura Fernández Cordero y Mabel Belluci, quienes abordaron el tema de la mujer anarquista y su discursividad.

Este trabajo se articula bajo este enfoque, aproximándose al estudio de uno de los actores políticos y sociales presentes a inicios del siglo XX, los anarquistas, pero alejándose de los estudios tradicionales de estos actores. Poco se sabe de la construcción de los sujetos anarquistas, en general los trabajos sobre los ácratas se focalizan mayoritariamente sobre la descripción histórica de ellos, su participación obrera o intelectual y en ocasiones, descripción y encuadramiento de los teóricos clásicos ${ }^{3}$, dejando de lado la construcción del sujeto anarquista y dando cabida a una idea generalizada de los libertarios, que muchas veces responde más a un construcción presente que a un relato y praxis anarquista.

En la revisión del campo historiográfico y las fuentes consultadas, se observa que salvo notables excepciones, los discursos y prácticas libertarias se han domiciliado lejos de las hazañas de grupos y clases que, no sin mérito, han ocupado las páginas escritas por la historiografía tradicional, la historiografía marxista clásica o en general en la historiografía del mundo obrero. En general para los discursos políticos militantes (y su historiografía), que prevalecieron durante el siglo XX, el cuerpo y la palabra de las mujeres ácratas fue un cuerpo ausente y solamente

\footnotetext{
${ }^{1}$ Carola Agliati y Claudia Montero, realizan un recorrido de las expresiones femeninas aparecidas en la prensa nacional. En su artículo "Explorando un espacio desconocido: prensa de mujeres en Chile. 1900-1920"1, observan la tradición patriarcal que invisibiliza los discursos femeninos, destacando el aporte de la prensa en la incursión femenina del espacio público.

${ }^{2}$ Buenos Aires: Editorial Contrapunto, 1990.

${ }^{3}$ Ver Ángel Cappelletti, Irving Horowitz, Sergio Grez, entre otros.
} 
ocuparon el papel de compañeras de ruta en los proyectos y gestas emancipadoras de sus contemporáneos varones o como telón de fondo de las mujeres destacadas.

El tema abordado en este artículo, representa una problemática femenina (concepto de por sí problemático), que contribuye a ampliar la perspectiva de la historia político social y que además de permitir la reconstrucción, de un aspecto de la historicidad de las mujeres libertarias, se presenta como un ejercicio de visibilización de las anarquistas rescatando la construcción del sujeto femenino revolucionario construido por y desde el anarquismo ${ }^{4}$.

En el ámbito temático, se contribuye a la vinculación existente entre la estructura doctrinaria y la práctica política de los anarquistas, en favor de una interpretación y comprensión integral del fenómeno histórico y de las características constitutivas de actores relevantes como fueron su identidad, praxis y discurso. El análisis de estos vínculos permitirá aportar a la cimentación del conocimiento sujeto femenino libertario revelado por los ácratas.

Se estima que los anarquistas, tanto en Chile como en Argentina, desde sus respectivas tribunas y aparatos culturales -de elaboración y transmisión- de discurso y praxis, buscaron configurar una subjetividad e identidad política, social y cultural de las mujeres, reconociéndolas como parte constitutiva de un sujeto histórico de cambio social, capaz de emanciparse integralmente en lo público y en lo privado. En esta línea deben mencionarse dos textos compilatorios de la prensa femenina anarquista de Argentina porque fueron publicaciones realizadas por mujeres. El primero de ellos la "Voz de la Mujer de 1897-1898" 5 y el segundo "Nuestra Tribuna Femenina" de 1920. Ambas compilaciones presentan todos los artículos publicados por mujeres anarquistas del periodo, resultando vitales para esta tesis.

Desde la historia política y social se hace especial hincapié en el análisis de los discursos y el contexto en que fueron construidas esas alocuciones y práctica. Se trabajó en torno a archivos de prensa de Argentina y Chile entre 1880 y $1930^{6}$, y se analizaron los discursos obtenidos. A partir de la densidad y frecuencia de ciertos tópicos se construyeron categorías analíticas discursivas. En éstas, es posible rescatar parte de las representaciones subjetivas de las mujeres construidas desde el anarquismo.

\footnotetext{
${ }^{4}$ Este artículo forma parte de la tesis de grado conducente al grado de Doctora en Estudios Americanos de la Universidad de Santiago. Está basado en artículos de prensa anarquista de Argentina y Chile. de principios del siglo XX.

${ }^{5}$ S.A. Buenos Aires: Universidad Nacional de Quilmes, 1997.

${ }^{6}$ Para el caso argentino, se trabajó en el Centro de Documentación e Investigación de la Cultura de Izquierdas en Argentina CEDINCI. Este trabajo, fue complementado con el levantamiento y recopilación de fuentes y archivos en la Federación Libertaria Argentina (FLA) y en la Federación Obrera Regional Argentina (FORA), donde se pudo revisar una serie de documentos correspondientes a Suplementos de La Protesta, Estudios, Martín Fierro, Germen, El Azote, Ciencia Social, La voz de los tiempos, Palotes, Germen, La Campana, La voz de los Tiempos y otros periódicos anarquistas. Sin duda, estas fuentes hicieron posibles grandes aportes a esta investigación, en tanto se encontraron una serie de artículos referidos a la temática de estudio.

En Chile, el trabajo se focalizó esencialmente en el levantamiento de fuentes de prensa. Se recopilaron diversos artículos de las publicaciones periódicas anarquista de mayor difusión aunque de heterogénea duración. Entre los periódicos revisados se encuentran Acción Directa, Verba Roja, El rebelde, El grito del Pueblo, El Proletario, La Batalla, El ácrata, La agitación de Santiago.
} 


\section{Consideraciones previas para un estudio de la mujer libertaria}

Los libertarios al igual que otras ideologías del período, surgieron en el contexto de la incorporación de los Estados (como superestructura política jurídica) y de las estructuras económicas (como modo de producción) de Chile y Argentina al capitalismo liberal y a la apropiación de un discurso pro civilizador por parte de las elites y los gobiernos de ambos países durante el siglo XIX. La implementación y consolidación de estos cambios políticos y económicos condujeron al surgimiento de nuevos actores sociales y a una mutación exponencial y rápida de la sociedad que abarcaron también a aquella no despreciable parte de la población compuesta por las mujeres. Existe en la actualidad un mayor consenso en reconocer que la necesidad de mano de obra provocada por la industrialización también significó la incorporación de las mujeres al ámbito laboral. Para los anarquistas, ellas al igual que los hombres que ingresaron a las industrias, sufrían de la misma explotación, pero a diferencia de ellos, esta incluso se profundizaba por su condición de mujer.

Paradójico fue, que al mismo tiempo que se intentó excluir a la mujer, estos factores condujeron hacia fines del siglo XIX a la emergencia y al ingreso de ellas al ámbito productivo capitalista y, como consecuencia de aquello, se produciría su incorporación a la participación político-social, fortaleciendo las filas del proletariado. Las mujeres, especialmente de extracción popular ampliaron su representación laboral y pública de modo creciente hacia los inicios del nuevo siglo.

A pesar de su significativo arraigo en los sectores artesanales, para los comunistas libertarios antiautoritarios el avance del capitalismo y el proceso de proletarización, resultó una coyuntura propicia para incorporarse en las fábricas, mineras y centros portuarios. Fue de esta manera, que en la medida que creció el movimiento de obreras y obreros también aumentaron su influencia en sus organizaciones, especialmente porque se inició el proceso de formulación y formación del sindicalismo revolucionario, con tendencias anti estatales. El surgimiento del anarcosindicalismo supuso que serían las y los trabajadores organizados quienes debían encabezar las luchas por la revolución social y esto debía ser sin la presencia de partidos y por supuesto sin gobierno.

En Argentina a diferencia de Chile, en los espacios obreros se destacaron públicamente varias mujeres en la dirección del movimiento o en la propagación de las ideas, lo mismo sucedió con el anarquismo, donde se ha logrado vislumbrar públicamente para el país trasandino un número significativo de mujeres militantes ${ }^{7}$. Para los libertarios el tema de las mujeres y su incorporación al trabajo fabril fue un asunto del cual se preocuparon, pero sin abandonar otros aspectos "Las mujeres anarquistas intentaron resolver el nuevo paradigma de la modernidad industrial: mujerobrera-madre. ${ }^{8}$ Este sería uno de los nudos que no serían fáciles de resolver para los anarquistas.

La relación sujeto-contexto, es la base para entender el proceso de desarrollo del anarquismo en Chile y Argentina, puesto que como señala Suriano

\footnotetext{
${ }^{7}$ Es probable que esto responda a la mayor presencia de ácratas al otro lado de la cordillera, permitiendo que las mujeres tuvieran una visibilización más significativa en el movimiento popular obrero argentino.

${ }^{8}$ Mabel Belluci, "De la pluma a la imprenta”, Mujeres y cultura en la argentina del Siglo XIX, Lea Fletcher compiladora, (Buenos Aires: Feminaria editora, 1994) 260
} 
...no es menos cierto que el rol de los mensajes ideológicos no deben ser analizados de manera aislada y perdiendo de vista quiénes son los sujetos que los expresan, cuál el contexto cultural y social en el que circulan (...) Desde esta perspectiva se infiere no sólo la contaminación de los mensajes libertarios, sino también las influencias externas, los cruces filosóficos, las prácticas conjuntas con otros sectores.....

Al abordar aspectos teóricos vinculados a la construcción del sujeto femenino en el marco del discurso libertario, se observan una serie de tensiones en su interior. Es relevante señalar en este plano, los componentes del discurso y la reflexión ácrata respecto de la mujer y para ello se presenta una propuesta de construcción analítica compuesta por categorías de análisis que se desprenden del propio discurso anarquista sobre las mujeres y desde las mismas.

Se manifiesta como clave analítica de entrada, la naturaleza peculiar y en ocasiones, sui generis del anarquismo, como un movimiento que si bien se desarrolló preferentemente al amparo del movimiento obrero, se ha constituido históricamente como una expresión ideológica, política y cultural, que presentó características propias y que por poseer en su interior diversas corrientes con múltiples directrices, resulta difuso e inexacto asumirlo como si fuera una sola integridad ideológica o incluso orgánica ${ }^{10}$. La no constitución de un partido político, la rotación de sus dirigentes, la presencia de muchas líneas estratégicas y las distintas formas de su accionar, fueron y son sin duda un problema a la hora de poder agruparlos bajo una trinchera de organización única.

Los ácratas se organizaron en distintas esferas, actuando mediante la propaganda por el hecho, la difusión verbal y escrita de sus principios, la defensa de principios como el antialcoholismo, la difusión del racionalismo ilustrado de raigambre emancipadora, la defensa de la mujer y la organización de múltiples actividades culturales. ${ }^{11}$

Para una mejor comprensión del anarquismo, hay que constatar y entender que el movimiento ácrata se instituyó en un sistema de pensamiento social que apuntaba a cambios profundos en la estructura de la sociedad y por tanto no representaba ni representa una tendencia de alcance inmediato. Una de sus principales finalidades residía en el reemplazo del poder del Estado, entendido éste como un organismo autoritario en sí mismo, por algunas formas de cooperación entre individuos libres y conscientes ${ }^{12}$ y por la persistente y profética difusión de La Idea.

El anarquismo es una forma de actuar desde el sujeto, pero en favor de la sociedad-comunidad, razón por la cual se presentaron en su interior contrastes permanentes que impidieron a los ácratas el desarrollo de una colectividad propia. Subordinado a la mirada que cada libertario traía consigo, se fue formando un imaginario colectivo anarquista, que logró insertarse en un sector de la sociedad.

\footnotetext{
${ }^{9}$ Juan Suriano, Anarquistas. Cultura y política libertaria en Buenos Aires, 1890-1910. (Buenos Aires: Ediciones Manantial, 2001) 27

${ }^{10}$ Adriana Palomera Valenzuela. "Subjetividad e identidad política y social de la mujer en prensa anarquista de comienzos del siglo XX”, Redes políticas y militancia. La historia está de vuelta, ed. Olga Ulianova, (Santiago: Ariadna Ediciones, 2009) 32

${ }^{11}$ Ver, Juan Suriano, Anarquistas. Cultura y política...

${ }^{12}$ Walter Montenegro, Introducción a las doctrinas políticas. (Ciudad de México: F.C.E, 1983) 173.
} 


\section{Debates sobre el sujeto femenino y el anarquismo}

\section{La mujer y el problema del sujeto}

Los ácratas, en la búsqueda de libertades individuales y para la sociedad en su conjunto, apuntaron a la construcción de un sujeto revolucionario que fuera capaz de romper con el orden político y económico establecido, pero sin dejar de lado la transformación social y cultural que imbricaba sujeto y sociedad. Este posicionamiento teórico fue acompañado siempre de una praxis libertaria que traspasaba la transformación del sujeto en toda su magnitud, llevando su discurso a todas las esferas de la sociedad. Supeditados a esta convicción, la mujer, el matrimonio y el amor libre se constituyeron en un pilar fundamental de su alocución con el fin de construir un sujeto libertario y con ello una subjetividad femenina que tuvo su antesala en los postulados ilustrados.

A modo de antecedente, haré una escueta referencia a la construcción del sujeto femenino ilustrado-moderno, momento, que a mi juicio, permitió que las mujeres quedaran sometidas bajo construcciones conceptuales que se habían erigido desde la ilustración. En estas, hombres y mujeres pasaron a formar parte de categorías totalizantes y muchas veces binarias que determinaron el lugar que ocuparían en el mundo contemporáneo y que responderían a lo que Kant llamaría la disyuntiva entre seres consientes de sí mismo y seres en "minoría de edad": Para este autor todo sujeto ilustrado, como seres con conciencia de sí mismos debían presentar características asociadas a su capacidad de razonar, por tanto la categoría ilustrado era antagónica a la condición de "minoría de edad", tipología con la cual se refería a aquellos hombres y mujeres que no habían alcanzado la capacidad de pensar autónomamente

La ilustración es la liberación del hombre de su culpable incapacidad. La incapacidad significa la imposibilidad de servirse de su inteligencia sin la guía de otro. Esta incapacidad es culpable porque su causa no reside en la falta de inteligencia sino de decisión y valor para servirse por sí mismo de ella sin la tutela de otro. ¡Sapereaude! ¡Ten el valor de servirte de tu propia razón! : He aquí el lema de la ilustración. ${ }^{13}$

Es interesante observar como este juicio -aun cuando hubo mujeres destacadas en ámbitos del poder político, cultural, social y económico- se convirtió mayoritariamente en uno de los principios que desvincularon a las mujeres y sus luchas de la acción política y cívica durante el siglo XIX, intentando recluirlas al ámbito privado y negándoles ser partícipes de los nuevos derechos adquiridos pos procesos revolucionarios del siglo XVIII y del siglo XIX

Un caso paradigmático fue el de Marie Gouze conocida por su seudónimo Olympe de Gouges. En 1791, llamó firmemente la atención sobre este punto, redactando la Declaración de los Derechos de la Mujer y la Ciudadanía, documento que buscó ilustrar y crear consciencia respecto de los abandonos y la invisivilización en que habían quedado las mujeres pos revolución francesa. En su preámbulo la autora convocaba a constituir una Asamblea Nacional con las madres, hijas, hermanas

\footnotetext{
${ }^{13}$ Immanuel Kant, ¿Qué es la Ilustración? En Filosofía de la Historia, (Buenos Aires: Editorial Nova, 1998$), 45$.
} 
Considerando que la ignorancia, el olvido o el desprecio de los derechos de la mujer son las únicas causas de las desgracias públicas y de la corrupción de los gobiernos, han decidido exponer en una solemne declaración los derechos naturales, inalienables y sagrados de la mujer, con el fin de que esta declaración, presente continuadamente en la mente de todo el cuerpo social, les recuerde sin cesar sus derechos y deberes. ${ }^{14}$

Es ilustrativa esta declaración porque con el fin de obtener el mismo lugar que los hombres, aceptaba no solo la conquista de derechos, sino también la adquisición de deberes, "Ninguna mujer se halla eximida de ser acusada, detenida y encarcelada en los casos determinados por la Ley. Las mujeres obedecen como los hombres a esta Ley rigurosa.” ${ }^{15}$ Claramente, esta posición crítica fue uno de los factores que la llevaron al reconocimiento público de una parte de los líderes de la revolución, pero fue también lo que cimentó su camino político en contra de los Jacobinos y determinó su destino al ser condenada a la pena muerte bajo la guillotina el año 1793 acusada de reaccionaria.

El problema del sujeto para el anarquismo tiene en la historiografía una asociación directa con la pregunta por el sujeto anarquista. Lejos de ser una obviedad el problema del sujeto se plantea entre dos definiciones, la del sujeto histórico y la del sujeto de la historia. El sujeto histórico como problema antropológico y ontológico ya había sido planteado por Kant quién relacionó la dimensión racional y racionalizable del sujeto. La segunda acepción se remite fuertemente a Hegel y luego Marx, específicamente como una definición del sujeto de la historia. Si la primera acepción es de naturaleza antropológica (genero-individuo humano) la segunda tiene implicancias políticas y filosóficas que se relacionan con la primera (un sujeto ontológico) pero no son sinónimos. Para los anarquismos la imbricación o entrelazamiento entre el ser antropológico e histórico-político del sujeto tienen referencias en todos los autores clásicos del pensamiento anarquista.

Aunque en las lecturas simplificadas del marxismo y del anarquismo la idea del sujeto aparece clausurada en planos ontológicos, ni los clásicos ni las elaboraciones posteriores, ni las prácticas políticas, proponen un sujeto absoluto aunque en el pensamiento en boga, especialmente durante la primera mitad siglo XX, fueran frecuentes las alusiones a un marcado componente estructural del cual derivaría la subjetividad.

La práctica política del anarquismo abrió el foco de atención sobre la naturaleza dinámica del sujeto histórico y sobre problemas como la contradicción, la negación y la creación de la subjetividad. La naturaleza marcadamente "profética” de los imaginarios redentores justifica nuestra interpretación dinámica de la noción de sujeto presente en los actores que estudiamos.

Brevemente podemos señalar que ni en la teoría ni en la práctica política existe un sujeto absoluto y es la dimensión social y política la que da un carácter generativo al sujeto histórico transformándolo en sujeto de la historia.

\footnotetext{
${ }^{14}$ Marie Gouze, (Olympe de Gouges). Preámbulo de la Declaración de los derechos de la mujer y la ciudadanía: 1791 [En línea]. Publicado en 19 de junio, 2007 [fecha de consulta: 6 de noviembre, 2014]. Disponible en: http://www.feministasconstitucional.org/sites/default/files/FRANCIADECLARACION_DERECHOS_1789_y_DE_ LA_MUJER_1791_\%28Olympe_de_Gouges\%29-1.pdf

${ }^{15}$ Marie Gouze, (Olympe de Gouges). Preámbulo de la Declaración...
} 
En la historiografía chilena, por señalar solo dos casos ilustrativos, tanto Gabriel Salazar como Sergio Grez han realzado la naturaleza dinámica del sujeto, su carácter integrador y su desborde político social expresado como "Bajo Pueblo", movimiento popular y clase para sí ${ }^{16}$. Con diferencias sustantivas ambos cuestionan el carácter estructural de la ontología marxista clásica presentes en la historiografía posterior a Julio Cesar Jobet y en las primeras obras de Luis Vitale.

Para Salazar el sujeto tiene una naturaleza indivisible social y política, no existe un sujeto doméstico y otro político y como proyección política la potenciación del sujeto histórico popular se da solo en el campo de la cotidianeidad.

El sujeto es así eminentemente social y se cuestiona históricamente la lógica estructural del marxismo clásico que propone que el proletariado sea un "ser" destinado ontológica e inevitablemente a hacer la revolución. En esta línea de pensamiento el sujeto es un ser social que ejerce como "actor social" que posee consciencia de sí desplegada en el curso de su acción. El sujeto no "es", está "siendo" en el ámbito de la estructura y de la cultura que produce.

La observación de la práctica política libertaria y de la producción de discurso dirigido a la mujer así como la acción de las mujeres anarquistas permite establecer una racionalización política de esta dimensión integradora como una dialéctica en que la contradicción capital-trabajo no se agota en la ontología del ser obrero. En la emergencia de la dialéctica sujeto-poder la subjetividad deviene, se "da" como proceso y no como "cosa" y particularmente como un proceso de subjetivación entre sujetos a nivel de campo práctico (político) y perceptivo. El sujeto y particularmente la mujer anarquista como sujeto emerge como constructo y como intersubjetividad. Los sujetos se construyen colectivamente en el espacio social de la contradicción que se devela en las luchas colectivas.

La práctica política de las organizaciones obreras, de grupos intelectuales, asociaciones políticas y personalidades públicas identificadas con el pensamiento libertario dio a la mujer un lugar como parte de la subjetividad histórica del cambio social. La tensión entre objeto-mujer como víctima de los males del orden capitalista y sujeto-mujer como actor del cambio definen una subjetividad que es igualmente realidad, constructo y necesidad. La mujer es destinataria del discurso, sin duda, pero es igualmente condición necesaria e insoslayable para un sujeto mayor. La praxis política debe llevar, en la profecía libertaria, de la mujer objeto a la mujer sujeto de la historia en el plano estructural, simbólico y político. En el taller y en la domesticidad, como compañera y como "compañerita", en lo público y en lo privado como "dadora" de sentido. En este plano el campo se abre y recorre un inevitable pensamiento de "época" tanto como un imaginario de vanguardia. Este amplio espectro, como continuum contradictorio, aloja tanto a la mujer madre caracterizada por la abnegación como a la mujer libre en su razón y su sexualidad.

\footnotetext{
${ }^{16}$ Para ilustrar esta discusión y sus matices ver Gabriel Salazar y Julio Pinto, Historia contemporánea de Chile, Tomo II: Actores, identidad y movimiento, (Santiago: LOM Ediciones, 2010); y Sergio Grez, Escribir la historia de los sectores populares con o sin la política incluida: A propósito de dos miradas a la historia social (Chile, Siglo XIX). Revista Política, Otoño, 2005, Vol. 44, 17-31.
} 
El sujeto, en esta dimensión dinámica, debía hacerse en el proceso de la praxis libertaria y no estaba garantizado fuera de ella. El sujeto era así sujeto político, social y solo en esa dimensión podía ser sujeto histórico y de la historia.

\section{Representación e imaginario de la mujer en los pensadores libertarios}

En el pensamiento y la polifónica representación de la mujer presente en el pensamiento libertario, es posible constatar la presencia de aquello que con frecuencia se denomina imaginario. El concepto se asocia de modo coloquial a la idea de mentalidad, conciencia colectiva o incluso ideología y es una forma de nombrar o referir las representaciones sociales. Para autores como Cornelius Castoriadis ${ }^{17}$ el imaginario y la representación son siempre sociales y no fenómenos intrapsíquicos o individuales. Como se verá, más allá de las diferencias que en el ámbito de la definición se puede encontrar entre las voces libertarias más consagradas, hay un núcleo común por contradictorias que ocasionalmente parezcan.

De Prudhon a Goldman, visto con los ojos del presente, hay un mundo de imaginarios contrastantes aunque en la pura representación se definan cada cual como emancipadores del mismo objeto y sujeto que nombran. Sólo hechas distinciones es posible comprender como comparten un mismo campo de significación representaciones de la mujer que en términos del imaginario son epocalmente tan dispares.

Sin duda no se agotará aquí el balance total de los pensadores que han tenido a la mujer como lugar central o periférico de sus enunciados; Se aporta ejemplarmente una parte de los más paradigmáticos convocados frecuentemente como autoridades del pensamiento y guías para la acción.

La reconocida diversidad del ideario ácrata, da espacio a una igualmente amplia variedad en cuanto al imaginario y representaciones de la mujer. Mientras unos se preocuparon ampliamente del tema, otros lo trataron esporádicamente. No obstante, se puede afirmar que la generalidad de los teóricos del anarquismo suelen coincidir en la idea de su emancipación, (así lo demuestran cartas, textos y publicaciones periodísticas de la mayoría de los referentes anarquistas que hablan sobre la mujer, el amor libre y la sexualidad como uno de los temas prioritarios para alcanzar la sociedad ideal).

En la génesis del anarquismo, una parte de los ácratas no quedaron ajenos al encuadramiento tradicional del nuevo sujeto femenino que surgió pos ilustración, Proudhon fue un fiel reflejo de estos representantes, señalando constantemente su desprecio a las mujeres. Para él la igualdad era un tema innecesario respecto a ellas "Después que habré establecido con hechos y documentos, la inferioridad física, intelectual y moral de la mujer; después que habré mostrado con ejemplos luminosos que eso que se llama su emancipación es lo mismo que su prostitución, sólo me restará determinar con otros elementos la naturaleza de sus prerrogativas, y a ocuparme en su defensa contra las divagaciones de algunas impuras, que el pecado ha vuelto locas”. ${ }^{18}$

\footnotetext{
${ }^{17}$ Olivier Fressard, El imaginario social o la potencia de inventar de los pueblos. Sciences de l'homme \& Sociétés, septiembre, 2005. $\mathrm{N}^{\circ} 50$.

${ }^{18}$ Pierre-Joseph Proudhon, Amor y matrimonio. [en línea]. Publicado en 1858, p. 51 [fecha de consulta: 23 de diciembre, 2014]. Disponible en: http: //www.antorcha. net/ biblioteca_virtual /filosofia/matrimonio/ indice.html
} 
Lo anterior versaba sobre la individualidad femenina, que partía de la base que las mujeres eran seres "menores”, sin embargo no agotaba ahí su fobia femenina, culpándolas también en su texto sobre el amor y el matrimonio por su escaso apoyo a la economía "El amor: se desea recíproco, fiel, constante, siempre igual, siempre adicto, siempre ideal. La mujer: ¡qué hermosa criatura si no costase nada, si a lo menos pudiese bastarse a sí misma, si con su trabajo pudiera pagarse sus gastos!" 19

Como se observa, Proudhon, siguiendo los parámetros culturales de la época, presentaba una visión crítica respecto de las mujeres, para él eran los hombres quienes al sacrificar su libertad, su fortuna, placeres y trabajo, sufrían una carga mayor con las féminas, puesto que estas siendo un mal asociado, costaban más de lo que producían. De acuerdo a su criterio las mujeres no se conocían a sí mismas ni eran capaces de llegar a hacerlo, porque esto era una labor privativa de los hombres.

Siguiendo los conceptos de la ilustración en torno al sujeto civilizado y la definición Kantiana sobre la minoría de edad, la mujer constituía para Proudhon un ser débil que difícilmente podía velarse por sí misma en términos materiales y espirituales: “...no está dotada de ninguna iniciativa, no distingue las circunstancias de las cosas; su inteligencia no actúa sobre sí misma, y sin el hombre, que le sirve de revelador y de verbo, no saldría de un estado primitivo". ${ }^{20}$

El genio (la inteligencia) era, pues, la virilidad del espíritu, su potencia de abstracción, de generalización, de invención, de concepción, de los cuales estarían desprovistos el niño, el eunuco y la mujer. Convivir entre estos dispares sujetos demandaba, en palabras de la época, la solidaridad de los dos órganos, y tal como el atleta se aleja de la mujer para conservar su vigor, el pensador se debía alejar también de ella para conservar su genio. No obstante, se daba por sentado un principio universal y natural de complementariedad en que "...cada hombre ame a todas las mujeres en su esposa, y que cada mujer ame a todos los hombres en su esposo. Es así como conocerán el verdadero amor y como la felicidad les será dulce”. ${ }^{21}$

La normalizada debilidad e inferioridad intelectual de la mujer se traducía en la incapacidad de producir universalismos y categorías, no podía en resumen pensar racionalmente por sí misma. Si bien podía en ciertas circunstancias recibir "La Idea” y de seguir con esfuerzo su deducción no podía ejercitar las virtudes de la razón en plenitud; no generaliza, no sintetiza, su espíritu era por definición y constitución antimetafísico:

si se le ocurre una idea, es un accidente fortuito, un hallazgo, de la cual ella misma no puede dar la demostración, ni la razón. De ello resulta que la mujer es incapaz de producir una composición regular, aunque sólo sea una simple novela. En el fondo, sólo percibe analogías; hace marquetería, improvisaciones; compone pistos y amalgamas. En la conversación no percibe el conjunto del discurso de su interlocutor; replica. A la última palabra. Por el mismo motivo no tiene potencia crítica: hará epigramas, rasgos de ingenio, sátiras y triunfa en la mímica; pero no sabe motivar, ni formular un juicio. Su razón es obscura como

\footnotetext{
${ }^{19}$ Proudhon, Amor y matrimonio... 68.

${ }^{20}$ Proudhon, Amor 68.

${ }^{21}$ Proudhon, Amor 68
} 
los ojos de Venus. La mujer ha contribuido abundantemente por su parte al vocabulario de las lenguas; pero no es ella que ha creado las palabras que sirven a las ideas abstractas, substancia, causa, tiempo, cantidad, relación, etc.; no es ella, por consiguiente, que ha creado las formas gramaticales y las particulares, como no ha inventado la aritmética y el álgebra. ${ }^{22}$

La mujer solo podía ser receptiva y por consiguiente relegada a la tuición del varón que la tuviese a cargo. Improductiva por naturaleza, inerte, sin habilidades especiales ni destacadas para las industrias ni el entendimiento, despojada de valores como la justicia y el pudor necesitará del padre, hermano, amante, esposo, de un amo-hombre que le provea por fuerza o influencia de las virtudes viriles, sociales e intelectuales: “...consideraba más importante la sociedad conyugal que el lazo fraternal y, por tanto, elevaba el adulterio a un delito de "lesa sociedad Además, correlacionaba sin titubear, la existencia de dos sexos diferenciados anatómicamente, el amor, su expresión en el matrimonio y, al fin, la procreación.” 23

En esas condiciones para este autor, las mujeres no podían igualar la potencia viril, lo que determinaba su subordinación. Solo el matrimonio se convertiría para él en la salvación de las mujeres

Por su naturaleza y ante la Justicia, pesa la tercera parte del hombre, de suerte que la emancipación que se reivindica en su nombre sería la consagración legal de su debilidad por no decir su esclavitud. La única esperanza que le queda es hallar, sin violar la Justicia, una combinación que la redima. Todos mis lectores habrán adivinado que esa combinación es el matrimonio. ${ }^{24}$

El sujeto femenino proudhoniano sin lugar a dudas estaba traspasado por su contexto, no obstante, esto no lo exculpa de ser reconocido como un misógino, alejándose de las futuras posturas ácratas sobre la mujer. En la medida que se desarrollaron otras experiencias anarquistas los postulados de Proudhon pueden ser asumidos como un dispositivo lejos de los principios que la mayoría de los autores van a elaborar desde la tribuna anarquista.

En adelante se examinará la posición de dos de los teóricos clásicos de mayor reconocimiento del anarquismo, Mijaíl Bakunin y Emma Goldman

Para Mijaíl Bakunin, la mujer como individuo y como componente de una institución era sujeto pleno de la emancipación y radicaban en ella igualmente todas las posibilidades humanas presentes y futuras. Para él un gran mérito del cristianismo fue la humanidad de todos los seres incluidas las mujeres. Los límites de la religión quedaban claros al ceñir la igualdad de todos los hombres al ámbito celestial, para un tiempo eterno por venir cuando era aquí en el presente y sobre la tierra donde esas caras aspiraciones debían ser carne. ${ }^{25}$

\footnotetext{
22 Proudhon, Amor 68.

${ }^{23}$ Laura Fernández Cordero, "Queremos emanciparos: anarquismo y mujer en Buenos Aires de fines del XIX” Revista izquierdas (2010) año 3, Número 6.

${ }^{24}$ Proudhon, Amor 77.

${ }^{25}$ Mijail Bakunin. Dios y el Estado, (Buenos Aires: Ediciones Terramar, 2008) 46.
} 
La libertad y las conquistas espirituales no eran menester individual si no colectivo y enmarcado en la existencia de un entramado social sostenido por instituciones y costumbres que eran obra de la sociedad misma. La libertad individual sólo podía advenir mediante la emancipación colectiva de hombres y mujeres como seres humanos. La conquista de la libertad era considerada parte de la ley natural que otorgaba un derecho natural que había sido violado por instituciones arbitrarias y opresivas que había que abolir no contra natura si no a favor de ella. Este era el caso cuando en defensa de la familia natural Bakunin llamaba a abolir la familia legal fundada en el derecho civil y la propiedad.

Para el Ácrata el matrimonio religioso y civil debía ser sustituido por el matrimonio libre que encarnaba la unión voluntaria y soberana de dos individuos mayores de edad que ejercían el derecho de unirse y separarse según su voluntad, intereses mutuos y las necesidades de su corazón “... sin que la sociedad tenga derecho de impedir su unión ni de mantener ésta contra los deseos de ellos... Ni la violencia de la pasión ni los derechos libremente reconocidos en el pasado pueden servir de excusa para que uno cometa un atentado contra el otro - y cada atentado que se cometa en este sentido será considerado como un crimen". ${ }^{26}$.

La inversión de la utopía cristiana y su radicación en el mundo terrenal debían ser acompañadas de los mecanismos que aseguraran la eliminación del peor de los males cual era la herencia de la propiedad y arribar a la adquisición de la igualdad de derechos políticos y socioeconómicos entre mujeres y hombres. "Por consiguiente, queremos la abolición del derecho familiar y del matrimonio tanto eclesiástico como civil-, (que están) vinculados inseparablemente al derecho hereditario" ${ }^{27}$

En su Circular a mis amigos de Italia Bakunin llamaba a rechazar por completo la intervención de cualquier autoridad en el establecimiento de la unión entre el hombre y la mujer. Solamente de ese modo se encontrarían más estrechamente unidos, fieles y leales ${ }^{28}$.

Dentro del cuerpo teórico del anarquismo, Emma Goldman,1869-1940 fue la representante femenina de mayor reconocimiento en el mundo ácrata, aunque no focalizó su alocución al tema preferentemente femenino, tuvo acercamientos teóricos hacia él, destacándose por su vehemencia en la defensa de las posiciones libertarias.

En comparación con los autores antes señalados la norteamericana Emma Goldman articuló una de las críticas más profundas, íntimas y sagaces del mundo ácrata respecto de las instituciones que, en base a representaciones instituidas socialmente como imaginario, configuraban la identidad y función social de la mujer. Desde el amor a la producción de la vida material Goldman articulaba el entramado de la sociedad capitalista industrial como lugar de subjetivación. Como una verdadera antecesora de la biopolítica develó como se tejía la red de

\footnotetext{
${ }^{26}$ Mijail Bakunin, Catecismo revolucionario. 1864-1867. En BERNARD, Thomas. Ni Dios ni amo: cita de los anarquistas [en línea]. Ciudad de México: Editorial Extemporáneos, 1970 [fecha de consulta 3 enero, 2015]. Disponible en http://nidiosniamocitasanarquistas.blogspot.com/

${ }^{27}$ Mijaíl Bakunin, Escritos de filosofía política. Tomo II [en línea]. 11 de noviembre 1874, p. 64 [fecha de consulta: 19 de enero, 2015]. Disponible en: https://es.scribd.com/doc/226103121/Mikhail-Bakunin-Escritos-de-FilosofiaPolitica-II-pdf

${ }^{28}$ Mijail Bakunin, Circular a mis amigos de Italia (1871). En VELASCO, Demetrio. Ética y poder político en M. Bakunin. Bilbao: Universidad de Deusto, 2008.
} 
necesidades de la producción y la acumulación del capital en la cual la mujer, hilaba su propia vida o mejor dicho la vida que, a ojos de Goldman, no le pertenecía. La radicalidad del discurso emancipatorio de Goldman llevó a la sospecha máxima la misma cultura emancipadora, sus vicios y sus trampas discursivas así como las limitaciones de los diversos campos teóricos de la época.

...sin tener en cuenta las teorías políticas y económicas que tratan de las diferencias fundamentales entre las varias agrupaciones humanas; sin miramiento alguno para las distinciones de raza o de clase, sin parar mientes en la artificial línea divisoria entre los derechos del hombre y de la mujer, sostengo que puede haber un punto en cuya diferenciación misma se ha de coincidir, encontrarse y unirse en perfecto acuerdo. ${ }^{29}$

Junto a la denuncia de la debilidad de la teoría, Goldman instaló un principio cognitivo adelantado por lejos a los recursos discursivos del mundo ácrata de sus contemporáneos; el principio de la comprensión como punto de partida de un reconocimiento intersubjetivo entre los sexos y por su intermedio de la construcción social. Ese es el punto de partida de la emancipación de la mujer por encima de la "igualación” de hombres y mujeres en el marco de la explotación del capital y la sumisión ancestral.

Para Goldman, como otros ácratas la emancipación haría de la mujer un ser humano en el verdadero sentido. “Todas sus fibras más íntimas ansían llegar a la máxima expresión del juego interno de todo su ser, y barrido todo artificial convencionalismo, tendiendo a la más completa libertad, ella irá luego borrando los rezagos de centenares de años de sumisión y de esclavitud”.. 30

Si bien la autora identificaba la emancipación de la mujer (en tanto objetivo) como la razón de ser principal que originó y guió el movimiento de la emancipación de la mujer (en tanto acción política), la praxis socio-política desarrollada generó un efecto perverso y superfluo, de aislamiento, figurativo y reflejo de la cultura varonil. Una versión acomodada a la pretensiosa actividad intelectual y política de ciertos grupos y lejos de las necesidades profundas y sensibles de las mujeres comunes de su época:

la convirtió en una criatura artificial, que tiene mucho parecido con los productos de la jardinería francesa con sus jeroglíficos y geometrías en forma de pirámide, de conos, de redondeles, de cubos, etc.; cualquier cosa, menos esas formas sumergidas por cualidades interiores. En la llamada vida intelectual, son numerosas esas plantas artificiales en el sexo femenino ${ }^{31}$

La consigna “iLibertad e igualdad para las mujeres!” lanzada, según Goldman, por los más valerosos y nobles espíritus de su tiempo fue el sol que iluminó un nuevo mundo en el cual las mujeres podían dirigir sus propios destinos aunando de paso "entusiasmo, valor y perseverancia en incesantes esfuerzos por parte de un ejército de mujeres, que combatieron todo lo posible contra la ignorancia y los prejuicios”.".

\footnotetext{
${ }^{29}$ Emma Goldman, The Tragedy of Woman's Emancipation, Mother Earth, marzo, 1906. V. 1, № 1, pp. 9-17

${ }^{30}$ Emma Goldman, 9-17

${ }^{31}$ Emma Goldman, 9-17

${ }^{32}$ Emma Goldman, 9-17
} 
Sin embargo en la radical perspectiva de Goldman la dinámica emancipadora, en tanto, enunciados y prácticas, habría fracasado en su cometido fundamental quedando pendiente "la necesidad de emanciparse del movimiento emancipacionista si desea hallarse verdaderamente libre. Puede esto parecer paradójico, sin embargo es la pura verdad". ${ }^{33}$

Goldman interroga “¿Qué consiguió ella, al ser emancipada? Libertad de sufragio, de votar. ¿Logró depurar nuestra vida política, como algunos de sus más ardientes defensores predecían? No, por cierto.” ${ }^{34}$ Pues el movimiento de emancipación habría traído efectivamente luna cierta nivelación económica entre la mujer y el hombre pero no le suministró la necesaria fuerza para competir con el hombre desgastando sus energías, tensionando su vitalidad y envileciendo su vida a fin de ser incorporada en el marcado de la mano de obra con magros resultados y en dispares condiciones de confianza, prestigio y remuneraciones.

La gran masa de muchachas y mujeres trabajadoras, ¿qué independencia habrían ganado al cambiar la estrechez y la falta de libertad del hogar, por la carencia total de libertad de la fábrica, de la confitería, de las tiendas o de las oficinas? Además está el peso con el que cargarán muchas mujeres al tener que cuidar el hogar doméstico, el dulce hogar, donde solo hallarán frío, desorden, aridez, después de una extenuante jornada de trabajo. ¡Gloriosa independencia esta! No hay pues que asombrarse que centenares de muchachas acepten la primera oferta de matrimonio, enfermas, fatigadas de su independencia, detrás del mostrador, o detrás de la máquina de coser o escribir. Se hallan tan dispuestas a casarse como sus compañeras de la clase media, quienes ansían substraerse de la tutela paternal. ${ }^{35}$

A la paradójica y desigual incorporación a la actividad productiva, en el marco de la explotación de la fuerza de trabajo, Goldman suma la crítica al modo de vida y la cultura de sumisión en la esfera pública y privada de manera plenamente articulada. El desciframiento de la institución matrimonial, como contrato, devela no solo la disociación con el sentimiento amoroso sino además su función como dispositivo de control que garantiza la soberanía del hombre en perjuicio de la mujer al mismo tiempo que es la alternativa para escapar a una solitaria penuria y estrechez económica incluso en el caso de las mujeres consideradas emancipadas.

En el mismo sentido Goldman rompió la idea de que el amor y la maternidad eran necesariamente sinónimos de esclavitud y subordinación, considerando absurdos los dichos del movimiento emancipatorio que argumentaban sobre el dualismo de los sexos en que el hombre y la mujer representaban dos mundos antagónicos. Igualmente absurda consideró la noción popular acerca del matrimonio y del amor como sinónimos, surgidos de los mismos motivos y llenando las mismas necesidades cuando por el contrario eran, a su juicio, completamente antagónicos. "Como la mayoría de los dichos y creencias populares, éste no descansa en ningún hecho positivo y si sólo en una superstición”. ${ }^{36}$

\footnotetext{
${ }^{33}$ Emma Goldman. 9-17

${ }^{34}$ Emma Goldman. 9-17

${ }^{35}$ Emma Goldman. 9-17

${ }^{36}$ Emma Goldman. 9-17
} 
Para Goldman el matrimonio, por el cual las mujeres eran educadas y ofrendadas de niñas, era un arreglo económico, un pacto de seguridad que en poco difería dl seguro de vida de las compañías comerciales pero en el cual ambas partes pagaban, en el fondo, el costo de su felicidad. Sin embargo el espurio arreglo se mantenía revalidado por las condiciones infames de la proletarización a la que la mujer aportaba una tasa de ganancia sustantiva.

"Hay seis millones de mujeres asalariadas; seis millones de mujeres que tienen el mismo derecho que los hombres a ser explotadas, robadas y a declararse en huelga; también a morirse de hambre. ¿Algo más, señor mío? Sí, seis millones de trabajadoras asalariadas en cada tramo de la vida, desde el elevado trabajo cerebral hasta el más difícil y duro trabajo manual, en las minas y en las estaciones de ferrocarril; sí, también detectives y policías. Seguramente su emancipación es ahora completa”. ${ }^{37}$

\section{Categorías de análisis para el estudio del discurso libertario ${ }^{38}$}

Las categorías analíticas que utilizamos, no son arbitrarias, en tanto se han construido para agrupar y examinar parte de las temáticas abordadas por los anarquistas en sus múltiples discursos referidos a las mujeres. Estas categorías sistematizan el discurso ácrata en torno a distintas esferas en las cuáles ellos se vincularon con el tema de la mujer, dando cuenta de la construcción de un sujeto femenino anarquista, sin embargo en este artículo se trabajará solo con dos de ellas: La mujer anarquista en el plano sociocultural y la mujer como un actor social

\section{La mujer ante lo sociocultural}

La mujer ante lo sociocultural es una categoría de análisis de aquellas afirmaciones y discursos que revelan un aspecto del imaginario social anarquista. Como veremos los ácratas parten de una premisa ética, la cual les llevó a una apelación constante a los valores morales que debían tener las mujeres obreras y marginadas, criticando constantemente el acercamiento a vicios como el alcoholismo que se entendían como un producto y elemento de degradación surgido de un orden social decrépito.

Incesantemente fueron reprochadas todas aquellas conductas de las mujeres que imitaban las tradiciones y el actuar de las féminas burguesas, asumiendo con esto que una parte importante de las prácticas y costumbres, la negación del matrimonio, el antifeminismo asociado a la burguesía, la crítica a la iglesia, la subordinación de la mujer que la mantenía como sierva y propiedad de los hombres y de las costumbres no podían si no ser barridos por "La Idea” y práctica regeneradora. Junto al componente moral se encontraba una crítica desde la posición de clase que pretendía que estas mujeres no se asemejaran a las burguesas teniendo por tanto el carácter de una afirmación de la identidad clase.

Frecuentemente se asociaron causalmente elementos como la ignorancia, la presencia de la iglesia y sus valores y la desmedrada situación de la mujer teniendo, esos aspectos, una presencia fuerte en la alocución anarquista dirigido hacia las mujeres a quienes no sólo se consideró

\footnotetext{
${ }^{37}$ Emma Goldman. 9-17

${ }^{38}$ Estas categorías fueron creadas con el fin de agrupar los discursos de los anarquistas hacia las mujeres y son partes de la tesis doctoral. Para mayor información ver Adriana Palomera "Subjetividad e identidad política..." 42-55
} 
permeable a la ideología burguesa y sus valores sino también el receptor privilegiado del influjo eclesial.

La crítica a la moral y costumbres burguesas generadas por el régimen económico son uno de los tópicos frecuentes en este plano en que el orden social era visto como la expresión de una descomposición que de arriba abajo corroía la sociedad por su inmoralidad:

Nuestro régimen económico, por un lado, y por el otro la enorme depravación de las costumbres, el libertinaje más escandaloso a que llegaron a entregarse las mismas clases privilegiadas, son efectos de una causa común que obliga a los individuos a colocarse bajo la égida de la ley, que, dicho sea de paso, jamás ha conseguido ni ha de conseguir la purificación de las costumbres, ni llevar la honestidad a los prostituidos hogares de nuestra época, porque esto es obra de la evolución, y la evolución es independiente de las leyes, pues para que éstas sean consignadas, es necesario que aquella se haya manifestado primeramente ${ }^{39}$

El cuadro descrito fue el que a juicio de los ácratas colocaba a la mujer en una situación de múltiple exposición y siempre sujeta a los intereses conservadores de la sociedad. En ese medio había sido educada lo mismo que el hombre y a pesar de sus conquistas políticas en ascenso no lograba aún revolucionar el carácter de su actividad "prisionera en las redes del hogar, quedará ahora prisionera en las redes de un conjunto de intereses conservadores que reforzarán aún más su carácter conservador". ${ }^{4}$

Como vemos la denuncia oponía libertad y resignación, siendo esa actitud pasiva el escollo a la emancipación, a esa resignada apatía los ácratas oponían una acción educadora y la denuncia de las condiciones y prácticas burguesas, especialmente las más conservadoras y apegadas a la tradición católica.

Me exaspera contemplaros desfilar en triste caravana, de Santas sin creencia, pero sí fanatizadas, por esas calles de dios; cubriendo vuestros cuerpos, de formas delicadas y enlutando vuestros rostros de bellas araucanas con esa inmunda saya que no conoció dios. Y enredando esas manos marfilinas en el rosario, para ir sin miramientos a uniros al rebaño de esa inmunda plaga que es la religión, no vaciláis que a cada paso, pisoteáis el gran progreso que este es el verdadero norte de nuestra evolución.. ${ }^{41}$

Se aprecia, entre los responsables de esa resignación no solo al pensamiento conservador y sus instituciones en general, específicamente la Iglesia, los curas y monjas, las escuelas católicas y hasta la creencia general en un ser superior actuaba en contra del cambio anhelado manteniendo el orden social para la posteridad.

La atada y sugestionada por las religiones no puede educar los hombres y las mujeres futuras. Y como esclava sólo puede contribuir a la perpetuidad de la

\footnotetext{
${ }^{39}$ Ciencia Social, Año II (2º́poca), № 06, diciembre de 1898, p. 91

${ }^{40}$ Estudios, Año III, No3. 20 de julio de 1917, 54.

${ }^{41}$ La Voz del Marino, 16 de junio de 1917. No3. p. 1.
} 
esclavitud. Más el día que la mujer se emancipe de la tutela clerical, ya no podrá soportar otro tutelaje que el de su razón y su conciencia.. ${ }^{42}$.

La vulnerabilidad económica y sexual de la mujer tenía un componente sociocultural al verse influenciada por los sistemas educativos conservadores y burgueses. Esto no era responsabilidad de la mujer pues se consideraba que ella era la primera víctima de los malos sistemas educativos que de niña a mujer la llevaban desde temprano, a la explotación burguesa si era proletaria y al convento de monjas para ser instruida y educada cerrando un círculo vicioso.

Al tomar estado la iglesia exige tan solo que sepa de memoria algunos embustes del catecismo; la ley civil le manda estar bajo el dominio del hombre, y los padres, especialmente las madres, solo saben aconsejarle tonterías, que la hacen más esclava y más hipócrita. Sobre esa pirámide del artificio y la ignorancia se sostiene la familia. ¡Cuánto falta que aprender!. ${ }^{43}$

En la crítica de la moral conservadora se denunciaba un "funesto fanatismo” que se percibía en el mundo femenino y que radicaba en la ignorancia a la cual había estado sometida la mujer a través de la dominación masculina.

...así que la mujer ignorante, incapaz de raciocinar, toma con frecuencia lo falso como verdadero, lleva hasta la exageración las teorías y prácticas religiosas, se hace fanática y lleva el fanatismo al seno de su familia, donde se deja sentir con todo el peso de sus consecuencias funestas ${ }^{44}$

Ese sentido común fanático era alimentado y alimentaba a su vez el influjo eclesial que la sustraía de una participación social y política.

Si hoy en día no reconocemos todo lo que ella hace, todo lo que influye en la vida de la humanidad, es porque, desgraciadamente, le hemos negado que pueda por su inteligencia estar con los hombres en las luchas del pensamiento y del adelanto humano; y esto por la rutina; triste cosecha de una religión y de unas costumbres que le han negado derechos y han rebajado su dignidad ${ }^{45}$

Este carácter de la sociedad clerical y conservador que a juicio de los anarquistas, hacía mella en las mujeres era el fruto del influjo del discurso eclesiástico que era parte del mecanismo de opresión hacia las féminas y debía ser denunciado y puesto en evidencia apuntando a la víctima de esa influencia. Un poema publicado en El Azote de 1909 acusaba ese llamado y denunciaba los abusos cometidos por los frailes en la inocencia o en otros casos la lascivia y corrupción de las mujeres que acudían a su apoyo moral y eventualmente económico.

Era evidente la crítica a la Iglesia como responsable de los dilemas morales con los cuales se cuestionaban a las mujeres y junto con ello la denuncia de inconsistencia, ignorancia e hipocresía de la institución que "está cimentada sobre el fango a nosotros nos parece que la está sobre la

\footnotetext{
${ }^{42}$ Verba Roja, Valparaíso, 1 de mayo de 1919. № 9, p. 6.

${ }^{43}$ Martín Fierro, Año I, N²2. 4 de agosto de 1904, p. 8

${ }^{44}$ Germen, Año I, No6. 1 de marzo de 1907, 173.

${ }^{45}$ El Azote, Año IV, No88. 17 de marzo de 1912, p. 3
} 
ignorancia y la sotana basada en la hipocresía” ${ }^{46}$ y que carecía de fundamento para validar entonces, con sus valores, la unión de las personas.

La ficción de aquellos vínculos, que se consideraban sagrados, palpitaban en la conciencia de quien los contrajera; y los quebrantaba, malogrado su idolatría por ellos. Así se desmoronaba aquel infierno que, santificado por la mano del clérigo, se llamaba hogar conyugal; así nacía la degeneración física y moral de las sucesiones, los hechos de sangre, la prostitución ${ }^{47}$

La crítica al matrimonio, desde esta perspectiva, no era remisible al ámbito individual o privado, se relacionaba con la situación social y económica al ser una vía de escape de una vida de privaciones y desdichas "La falta de trabajo en el "marido", lo escaso de la remuneración, las enfermedades, etc., hacen que lo que en otra circunstancia sería el colmo de la dicha, sea en nuestra condición una grave y temible carga, para los “esposos”. 48

La voz de la Mujer de 1896, muestra el caso de una mujer que no pudo con la terrible carga de su condición y como otras fue arrastrada por una moral ‘despreciada’ lo cual la llevó a cometer

Arrebatos de la pasión, violencias del temperamento, hiciéronla caer. Palpitaciones lascivias de la carne empujáronla a entregarse ciega en brazos de un amante. Amor o lujuria, o las dos cosas a la vez, lleváronla a romper la venda de la virginidad. Pecó, y la conciencia posterior de su pecado ha removido todo su ser. Pesan sobre ella los estigmas de una moral aceptada generalmente, y la sociedad entera la desprecia y maldice. ${ }^{49}$

Sin embargo socioculturalmente la crítica no era restrictivamente moral sobre la individualidad de la mujer, era una crítica política al conjunto del sistema y a quienes desde él se hacían parte del flagelo y que eran más deleznables por su función y posición que las mismas prostitutas que eran sus víctimas y que podían ser consideradas trabajadoras de una actividad noble y requerida socialmente. El Azote hacía la comparación entre un fraile y una prostituta dando más crédito a esta última por su aporte a la sociedad.

En esta última condición se halla el fraile. Este, en cambio del dinero que recibe, solo ofrece misas, oraciones, cánticos, hipótesis, quimeras y esperanzas, es decir, todo lo que no tiene valor ni utilidad alguna. La prostituta al contrario: no sólo es un factor útil sino esencial en la sociedad: ella satisface una necesidad orgánica de primer orden, una de las funciones más nobles ${ }^{50}$

La misma comprensión a las prostitutas no era prodigada a la promiscuidad de la clase alta, su libertinaje hedonista y como bajo su influencia las mujeres del pueblo se veían permeadas por esas prácticas. Nuevamente el problema no era de la intimidad, era social y hasta de salud pública. La comparación entre el placer hedónico de clase alta y la lujuria arrebatada de los de

${ }^{46}$ El Azote, Año IV, №105. 21 de julio de 1912, p 3.

${ }^{47}$ Ciencia Social, Año II (2 época), № 11, junio de 1899, p 171.

${ }^{48}$ La Voz de la Mujer, Año I, No1. 8 de enero de 1896, pp. 7-8.

${ }^{49}$ Ciencia Social, Año II (2 época), No 12 , julio de 1899, p 190

${ }^{50}$ El Azote, Año IV, No 88.17 de marzo de 1912, p. 1 
abajo colocaba el tema de la lucha de clases y sus consecuencias en el tapete mostrando desde este tópico el orden social corrupto.

Lo mismo en las grandes que en las pequeñas ciudades, en la capital y en la aldea, las clases supuestas distinguidas se degradan en el lupanar; los burgueses adinerados y los burgueses sin blanca se roban sus mujeres, se refocilan con sus criadas y caen en todas las bajezas de la holganza y de la lascivia; obreros y campesinos se embrutecen en la taberna y gozan de la carne como bestias. Y mientras las mujeres del gran mundo regalan su carne lujuriosa en la más espléndida promiscuidad, las mujeres del pueblo yacen panza arriba continuamente dispuestas a ser fecundadas al menor roce del macho ${ }^{51}$

La emancipación de la mujer de todas estas situaciones consideradas lacras sociales debía partir por la autonomía en el pensamiento y en la acción. Sin embargo se denunciaba que la emancipación femenina había sido una situación estancada en la narrativa ya que la responsabilidad de los males no solo estaba en los varones, los burgueses y los curas. La mujer debía tomar conciencia y parte.

Es necesario entonces, buscar la emancipación moral de la mujer, dándola un puesto de responsabilidad directa en los acontecimientos de toda índole, a fin de que vaya formándose un concepto propio y exento de prejuicios. Hasta ahora, se ha usado el halago para convencerla, del elogio taimado para poseerla, de la mentira convencional para gastarla, pero no se la ha insinuado siquiera la obligación de su propia defensa como ente de sentimientos libres ${ }^{52}$

Una mirada introyectiva a la personalidad y carácter de la mujer podía explicar el por qué la mujer cobraba sentido en función de “otro” situando en la educación el problema pero igualmente en cierto feminismo que actuaba paternalistamente. "Como hija, solo llora el dolor de sus padres, como novia solo siente la amargura de su novio, como madre, egoístamente, solo se emociona ante el desamor del fruto de sus amores.”53

La crítica hacia el feminismo burgués era dura, desconfiada y radical acusándolo de ser expresiones pomposamente emancipadoras de la mujer, que no intentan otra casa que sumirla en la mansedumbre y resignación de los siervos:

...anulando su voluntad con torpes halagos; embruteciendo su entendimiento con viles concesiones; empequeñeciendo su espíritu con groseros artificios, llevando sus aspiraciones hacia todo lo mísero, lo vano, lo inútil, y haciéndola temer o despreciar lo positivo, lo beneficioso; entregándola al hombre no como su compañera, sino como su hembra, y para mayor escarnio recomendándole la consideración hacia ella! ¡Cómo si en un concubinato, y lo es la unión de dos almas desemejantes, pudiera haber otra cosa que tirano y sierva! ${ }^{54}$

\footnotetext{
${ }^{51}$ Ciencia Social, Año II (2º́poca), № 12 , julio de 1899, p. 180

${ }^{52}$ Palotes, Año I, No4, 15 de febrero de 1930, p. 12

${ }^{53}$ Palotes, Año I, No4, 15 de febrero de 1930, p. 12

${ }^{54}$ La Voz de la Mujer, Año I, N². 31 de enero de 1896, p. 4
} 
Se creía que estos movimientos acusados de conservadores, con el triunfo político del feminismo serían más adelante contrarios a la causa, cómplices del hombre al perseguir sus objetivos y gastar las energías y confianza de las mujeres que "Educada la mujer en el ambiente conservador de las leyes y de los intereses actuales, leyes e intereses que el hombre comienza a combatir, no es dudoso se llegue a dar forma a monstruosas tiranías; es posible que lleguemos a perder una gran parte del dominio que hemos conquistado sobre nuestras acciones y nuestras ideas.” 55

Para 1930 el periódico Palotes planteaba que la estrategia no estaba solo en convencer al hombre sobre la emancipación femenina, sino en apelar a la misma mujer para su propia liberación evitando el peligro de desviar la lucha y corromperla ante los intereses masculinos o simplemente ganar en masa para la causa. "Hemos llamado constantemente al corazón de los hombres, pero nunca se nos ha ocurrido tocar el aldabonazo de la advertencia a las puertas del sentimiento femenino, como si su existencia corrieses simplemente atada a las exigencias más o menos torpes del masculinismo.” 56

\section{La mujer como actor social}

En general, los anarquistas aluden a las obreras y oprimidas, resaltando la importancia de las mujeres trabajadoras y la necesidad de la unión de éstas para ayudar a cambiar el sistema capitalista. Se las interpelaba a jugar un rol más activo frente a la marginación social, política, económica y cultural, llamándolas a reconocer lo vital de su desarrollo educativo. Se apelaba al deber crítico de las mujeres, y aunque en algunos casos se interpeló a todas, principalmente manejaron un discurso de clase, esencialmente traspasado por la persistente crítica al sistema capitalista y sus leyes burguesas.

En este sentido las fuentes indican una crítica desde una posición de clase más que una de género.

Y vosotras, infelices compañeras nuestras que os matáis todo un día para hacer una docena o dos de camisetas, por las cuales se os paga la veintésima parte de lo que luego ellos cobran, ¿creéis que eso es justo? Si reclamáis no os atenderán y lo que es más probable os despedirán, no os darán más trabajo, si os declaráis en huelga, la perderéis, y si la ganáis, no tardaréis en estar en peores condiciones, porque la evolución de los demás gremios hará nulo vuestro triunfo, no, no haréis nada si nos os rebeláis contra los ladrones. Destruyendo es como se puede derrumbar el mundo de la explotación. Imitad nuestro ejemplo. Rebeláos abierta y francamente, sin ambages, sin términos medios ${ }^{57}$

También, como consolidación de una posición típicamente política que se busca difundir, suelen presentarse artículos de mujeres próceres del anarquismo internacional, féminas que habrían sido capaces de reconocerse como actoras sociales y políticas como Emma Goldman y Luisa Michel.

En su mirada de mundo, se consideró que ellas no eran ajenas a la emancipación universal. La emancipación era entendida desde la negación de las barreras cotidianas hasta las barreras políticas económicas y religiosas. Una arenga hacia la liberación femenina de 1907 señalaba:

${ }^{55}$ Estudios, Año III, No3. 20 de julio de 1917, 55.

${ }^{56}$ Palotes, Año I, Nº4, 15 de febrero de 1930, p. 12

${ }^{57}$ La Voz de la Mujer, Año I, Nº4. 27 de marzo, 1896, p. 5 
Pero la civilización, cumpliendo su misión regeneradora, hace penetrar un rayo de luz en las lobregueces de las inteligencias femeninas, y con una voz que como ariete abre grietas y conmueve la fortaleza de las vulgaridades y rutinas, dice á la muger: caminad vosotras también por la senda de la perfección, reclamad vuestro puesto en el mundo del pensamiento, educad, vosotras á los que mañana regirán la sociedad, y de este modo acelerareis el día en que yo reine como soberana del mundo, derramando mis inestimables bienes en los senos de la humanidad. ${ }^{58}$

Invitar a la organización y unión de las mujeres a favor de estudiar y protestar junto a los hombres contra las injusticias impuestas por el sistema, se convirtió en un aspecto fundamental de la convocatoria ácrata. Por un lado, el llamado se hacía a la autoformación, y por otro, se dirigía a los varones para que contribuyeran en esta tarea, acercándolas a los libros y a la instrucción.

El primer número de la Voz de la Mujer instaba en 1896 a la lucha por la liberación femenina en los siguientes términos:

Y bien: hastiadas ya de tanto y tanto llanto y miseria, hastiadas del eterno y desconsolador cuadro que nos ofrecen nuestros desgraciados hijos, los tiernos pedazos de nuestro corazón, hastiadas de pedir y suplicar, de ser el juguete, el objeto de los placeres de nuestros infames explotadores o de viles esposos, hemos decidido levantar nuestra voz en el concierto social y exigir, exigir decidimos, nuestra parte de placeres en el banquete de la vida. ${ }^{59}$

Si para el sujeto femenino, la crítica al capitalismo, la sociedad burguesa, el conservadurismo y la búsqueda del amor libre y la sexualidad sin contrato, requerían de una educación plena y organización, la victoria oral de esos valores y objetivos debía derrotar a una institución fundamental: La iglesia y la religión católica.

Hasta ayer hemos suplicado a un Dios, a una virgen u otro santo no menos imaginario el uno que el otro, y cuando llenas de confianza hemos acudido a pedir un mendrugo para nuestros hijos, ¿sabéis lo que hemos hallado? La mirada lasciva y lujuriosa del que anhelando cambiar de continuo el objeto de sus impuros placeres, nos ofrecía con insinuante y artera voz un cambio, un negocio, un billete de banco con que tapar la desnudez de nuestro cuerpo, sin más obligación que la de prestarles el mismo.. ${ }^{60}$

Las definiciones políticas antagónicas especialmente con la Iglesia y el Estado, entendidos como sostenedores y cómplices del capital, servían de punto de partida, doctrinario y político, frecuentemente para explicar el por qué se asumen como comunistas libertarias.

Y fue entonces también, que desconocimos a ese Dios y comprendimos cuán falsa es su existencia; en suma, que no existe. Fue entonces que compadecimos

\footnotetext{
${ }^{58}$ Germen, Año I, Nº6. 1 de marzo de 1907, p. 172

${ }^{59}$ La Voz de la Mujer, Año I, No1. 8 de enero de 1896, p. 1.

${ }^{60} \mathrm{La}$ Voz de la Mujer, Año I, No 1.8 de enero de 1896, p. 1.
} 
a nuestras caídas y desgraciadas compañeras. Entonces quisimos romper con todas las preocupaciones y absurdas trabas, con esta cadena impía cuyos eslabones son más gruesos que nuestros cuerpos. Comprendimos que teníamos un enemigo poderoso en la sociedad actual y fue entonces también que mirando a nuestro alrededor, vimos muchos de nuestros compañeros luchando contra la tal sociedad; y como comprendimos que ése era también nuestro enemigo, decidimos ir con ellos en contra del común enemigo, mas como no queríamos depender de nadie, alzamos nosotras también un girón del rojo estandarte; salimos a la lucha... sin Dios y sin jefe.

He aquí, queridas compañeras, el porqué de nuestro periódico, no nuestro sino de todos, y he aquí, también, por qué nos declaramos COMUNISTAS ANÁRQUICAS proclamando el derecho a la vida, o sea igualdad y libertad. ${ }^{61}$

Otro componente de la autonomía y construcción del discurso político como más clase remite a la crítica a la hegemonía educativa hecha en las escuelas por la burguesía. Las mujeres ácratas de preguntan

No siendo libre la educación y no pudiendo disponer de tiempo suficiente para adquirirla ¿cómo vamos a ser educadas? ¿Quién ignora que desde nuestra más temprana edad el taller nos traga y martiriza? En él no es donde nos podemos educar, muy al contrario, allí hay de todo, de todo, menos eso... iy cien y cien veces hemos visto víctimas de la lubricidad burguesa las míseras obreras, bajar rápidamente en horribles tumbos y caer despeñadas al abismo del vicio, que cada vez más hambriento e insaciable las trabaja, cubriéndolas de cieno y lágrimas, que, niñas casi... que apresuraban por sí mismas su caída, para con ella librarse de la rechifla y el escarnio de sus mismos verdugos!.... ${ }^{62}$

En esta misión redentora las mujeres no dejaron de dirigirse a aquellos hombres anarquistas que habían dicho que se podía prescindir de la emancipación femenina llamándolos

señores cangrejos y no anarquistas" anunciándoles que "esta máquina de vuestros placeres, este lindo molde que vosotros corrompéis, ésta sufre dolores de humanidad, está ya hastiada de ser un cero a vuestro lado, es preciso, ¡oh!, ¡falsos anarquistas! Que comprendáis un vez por todas que nuestra misión no se reduce a criar vuestros hijos y lavaros la roña, que nosotras también tenemos derecho a emanciparnos y ser libres de toda clase de tutelaje, ya sea social, económico o marital ${ }^{63}$

No sólo contra los compañeros anarquistas lanzaban las mujeres sus diatribas, la dominación del hombre hacia la mujer se vive, dirá La Voz de la Mujer, cotidianamente, desde aspectos evidentes como otros más implícitos. Se crítica entonces el capricho del marido que comparte sólo momentos de pesar, quiere atenciones domesticas, sexo y favores que si no los tiene los buscará en otra dejando a su mujer en el olvido,

gastando en orgías con otras mujeres el tiempo y el dinero que sólo deberían ser para ti, lo primero para gozar y lo segundo para llenar las necesidades más

${ }^{61}$ La Voz de la Mujer, Año I, No 1.8 de enero de 1896, p. 1-2

${ }^{62}$ La Voz de la Mujer, Año I, №1. 8 de enero de 1896, p. 9.

${ }^{63}$ La Voz de la Mujer, Año I, No2. 31 de enero de 1896, p. 1. 
apremiantes de la vida; y aun siendo así no te quejes, pues si lo haces con tu marido recibes indiferencias o palos y si te quejas a tus padres no hacen más que compadecerte y decirte que tengas paciencia, puesto que nada es duradero y una vez muertos todo se acabó ${ }^{64}$

La arenga femenina también debía dirigirse a los varones junto a las mujeres para llamarlos hacia la revolución social oponiendo su miseria a los privilegios del rico y sus lujos ostentosos. También se explica por qué se adhiere a los principios anarquistas desde las mujeres.

A vosotras, compañeras de trabajo e infortunios, me dirijo, a vosotras que sufrís como yo la doble esclavitud del capital y del hombre.

Algunas de nosotras hemos abrazados el bello ideal anarquista porque comprendemos que sólo con la amplia libertad que ésta proclama, podemos ser felices. $^{65}$

Junto a los llamamientos, siempre cargados de dramatismo, para cambiar el sistema capitalista burgués, también, suelen presentarse con frecuencia artículos de mujeres próceres del anarquismo internacional, féminas que habrían sido capaces de reconocerse como actoras sociales y políticas como Luisa Michel y Emma Goldman de quien se señalaba como una de sus características más salientes era “...su sentimiento de la justicia profundamente desarrollado. Donde la justicia y la dignidad humana eran pisotear, estaba la Goldman en primera línea para protestar con ardiente palabras contra la injusticia, la injusticia, indiferente a todas las consecuencias personales.” 66

En su mirada de mundo, se consideró que ellas no eran ajenas a la emancipación universal. Su auto concepto era de “alma de la humanidad”. La emancipación era entendida desde la negación de las barreras cotidianas hasta las barreras políticas, económicas y religiosas: “¡Libertad, libertad, ideal de soñadores visionarios de un mundo mejor. ¿Cuándo serás realidad?... Y así, entonamos salmos a la libertad, sigamos adelante siempre mirando el porvenir. ${ }^{67}$

Nosotros, que por experiencia conocemos el alcance de todas las palabrerías que emanan de los labios de los políticos, no hacemos otra cosa que vociferar contra la política, que hoy como ayer, está abriendo la fosa que ha de sepultarla para siempre.

Ahora tú, compañera estudiante, medita un poco sobre los hecho, contempla la inmundicia que se oculta bajo el nombre de partidos políticos, y piensa que es a ese fango inmundo y corrompido, donde pretenden conducir a la mujer, las leaders feministas. ${ }^{68}$

Sin embargo para algunos contemporáneos la condición sentimentalista de la mujer la condenaba a situarse al margen de ciertos procesos revolucionarios. Su destino como actor social estaba cuestionado por el sentido común y el prejuicio de su inferioridad racional e invalidez política.

\footnotetext{
${ }^{64}$ La Voz de la Mujer, Año I, No3. 20 de febrero, 1896, pp. 7-8

${ }^{65}$ La Voz de la Mujer, Año I, No7. 14 de noviembre, 1896, p. 10.

${ }^{66}$ Acción directa, 1 de mayo de 1924. №30. p. 4.

${ }^{67}$ Luisa Arratia, “¡Libertad!”. En Acción Directa, Santiago, $1^{\text {a }}$ quincena de noviembre de 1922. № 18, 2.

${ }^{68}$ Verba Roja, $2^{\circ}$ quincena de septiembre de 1922. N $^{\circ} 42$, p. 3.
} 
La condición psicológica de la mujer, digan lo que quieran los feministas irreflexivos, es poco apta para la construcción de modalidades revolucionarias en los pueblos; tenemos una prueba en sus luchas y pretensiones que no son más que simples imitaciones de una actividad vieja de los hombres. El sentimentalismo que forma el carácter más saliente en la mujer, es una cualidad, buena si se quiere, pero de esencia conservadora ${ }^{69}$

Sin embargo en contraposición a esta afirmación taxativa, La Campaña en 1919 destacaba a la mujer en su condición de obrera y de soldado(a) que se hace parte de una guerra pues ella es "soldado y obrero; empuña el fusil y maneja el arado, ... en las fábricas sórdidas y las oficinas particulares y del Estado... ¿ ¿Tiene algún valor esa emancipación ficticia que desata a la mujer de un odioso tutelaje, que la libra del infierno del hogar para subyugarla al presidio del taller? ${ }^{70}$

La politicidad de clase que integraba todos los temas en una lucha mayor se expresaba en una arenga en La Voz de los Tiempos llamando a la movilización femenina contra el patriarcado y la proletarización del pueblo que es causante de todos los males.

Ya ha sonado la hora en que debemos ser algo más que la débil autómata, la incubadora de hijos, la esclava del hombre; otros deberes, grandes y nobles también, nos reclaman cumplimiento: es exigir los mismos derechos y deberes que el hombre. Debemos reclamar nuestro sitio en la gran lucha universal contra la sociedad burguesa. ${ }^{71}$

Más allá de los universalismos de la amplia unidad de la clase y las luchas comunes se pensaba que era a través del anarquismo que la emancipación femenina se materializará y no a través del feminismo burgués. Sin embargo la educación para el anarquismo debía hacerse en los cánones del mismo anarquismo y no en los de la fuerza "Eduquemos a la mujer para el anarquismo. Pero no a la fuerza, porque entonces, su inconsciencia sería también un peligro mayor que su indiferencia o su desagrado. ¡Hombre, dignifica a la mujer, y la mujer te escuchará complacida de saber que la quieres libre!" 72

El desarrollo de la mujer se imaginaba como el resultado de un proceso de instrucción libre y emancipador alejado de los centros de enseñanza “donde la mujer recibe una instrucción rutinaria y deficiente, llegando á su inteligencia la verdad mutilada y el error ensalzado, glorificado lo inútil, desfigurados los hechos por importantes que sean, siempre que les convenga ocultarlos; enseñanza monopolizada por el catolicismo á los que entran bajo su dirección” ${ }^{73}$. Se promovía una instrucción llamada verdadera, útil y racional para permitir el desarrollo de facultades superiores que le permitieran reflexionar, tener criterio recto y hacer de su inteligencia un aporte para su familia y la sociedad moderna.

\footnotetext{
${ }^{69}$ Estudios, Año III, No3. 20 de julio de 1917, p. 53.

${ }^{70}$ La Campana, Año I, No2. 13 de julio de 1919, p. 22.

${ }^{71}$ La voz de los tiempos, Año I, Nº5. 5 de julio de 1927, p. 13.

${ }^{72}$ Palotes, Año I, N 4, 15 de febrero de 1930, p. 13.

${ }^{73}$ Germen, Año I, Nº6. 1 de marzo de 1907, p. 174
} 


\section{Conclusiones}

Los ácratas, profetas de la revolución social, amantes de la libertad y el amor libre desecharon, en su discurso y en su acción no sólo el orden económico capitalista, abominaron también de la cultura y los valores que la burguesía imprimía en la sociedad mediante sus instituciones. Propiedad y Estado, Matrimonio e iglesia, guerra y policía, superstición e ignorancia fueron los medios y resultados del dominio burgués a derribar, en una larga marcha que involucró al individuo entero en lo privado y en lo público.

En la realización de "La Idea” la realidad de la incorporación de la mujer a las actividades productivas, colocó a los y las ácratas el desafío de mirarse como un conjunto que debía reconocer y proyectar la construcción de un sujeto íntegro del cambio social. Las mujeres no fueron sumadas a la tarea revolucionaria, ellas fueron parte de ella, e hicieron ver ante sus camaradas varones y ante ellas mismas que no había revolución sin emancipación y esta se hacía en el hogar y en la fábrica, en la lucha y en el amor, destrabado de prejuicios y violencias impuestas por un orden que inventado por hombres les dominaba a todos por igual.

La configuración de un sujeto femenino ácrata no fue nítida ni homogénea, el discurso no podía apelar a la liberación si no emprendía la tarea de educar para emancipar incluso en el interior de las filas libertarias. Una cultura burguesa en el marco de sociedades excluyentes no era el único obstáculo, la tradición, los valores, la dependencia económica de muchas mujeres, la sobreexplotación, la violencia y el abuso, la religión, el matrimonio y la potestad del padre y el esposo, el machismo presente en el movimiento obrero y sus organizaciones y el recelo de muchos camaradas libertarios, amparados por supuestos conocimientos científicos que avalaban la "fragilidad" de la mujer, las llevaba a ser muchas veces valoradas como hermanas, madres y “compañeritas” pero no como iguales, ahí también debieron luchar ese derecho, en el marco de una diferencia que ellas también reivindicaban.

A diferencia del feminismo burgués, con matices entre Argentina y Chile, la lucha principal y su contradicción principal era la existencia de las clases y no de los géneros aunque en las organizaciones Argentinas se enunciara con más fuerza ese discurso. La búsqueda de una identidad política y social revolucionaria, propia de las ideas libertarias, fue más importante que las ideas de participación política sufragista o de derechos ciudadanos, defendidos por personas o grupos feministas de la época.

La Interpelación a la mujer estuvo sumida en variantes que sacralizaban al mismo tiempo que reivindicaban su posición, a la par que el hombre, en la lucha por la liberación y unidos en "fraternal amor". Sin duda y a pesar de las contradicciones que se han develado, se trató de una experiencia de reflexión y praxis radical, que habló fuerte desde una tribuna donde las mujeres ocuparon un sitial destacado a pesar de todos los determinismos culturales masculinos que traspasaron a libertarios y libertarias.

Más allá de las amplísimas concepciones teóricas de algunos de sus clásicos, los ácratas situaron tanto en Chile como en Argentina a la mujer desde una subjetividad de clase abriendo el debate sobre tópicos que les eran propios y que nutrían el conjunto del ideario ácrata. 
El proceso vivido "en el interior" del mundo libertario, en tanto tribuna redentora de la mujer obrera y popular, no declamaba solo para una audiencia anarquista. El destinatario y la destinataria principal eran las mujeres populares las que debían reconocerse y verse a sí mismas como actoras de un movimiento social y político popular surgido en torno a la cuestión social, para llegar a identificarse con el movimiento obrero y con las ideas libertarias.

El anarquismo vio en las ideas de progreso y civilización, la necesidad de instrucción y auto educación para la mujer, la única forma de liberarse de su condición de marginación política y económica, ante un poder capitalista, que las postergaba y las limitaba a la subordinación social, moral, económica y cultural masculina. La tribuna anarquista, en su discurso, reflexión y praxis, criticó la pasividad y la resignación, llamaron a actuar y tomar posición frente al sistema. Mostraron una práctica sistemática y sostenida para movilizar a las mujeres en el sentido de ir reconociéndose como actoras políticas y sociales. En ese contexto la toma de conciencia, la construcción de un movimiento político y la emancipación de la mujer eran los pilares que hacían garantía del cambio social.

El discurso femenino y la idea de un Sujeto femenino se construyeron desde la concepción ideológica propia de los anarquistas, dando vitalidad a lo que he denominado una "Subjetividad femenina militante" que apelaba al reconocimiento y visibilidad de las mujeres mediante una prensa anarquista, tuvo una amplia producción de artículos destinados a las mujeres.

Desde el imaginario ácrata, se establece la existencia de la mujer como Sujeto Femenino Histórico en tanto enjuiciamiento del deber ser tradicional y la autoconstrucción del deber ser de la mujer futura. La dimensión de la emancipación de lo privado a lo público en la construcción de sujeto femenino libertario se expresó en nuevas ideas sobre la sexualidad femenina y el amor libre que apuntaban a la articulación de una teoría y una praxis que desembocaría en la Mujer como un Actor Social desde una posición de clase desde lo femenino.

Para finalizar las palabras de Severino Di Giovanni. Desde mi punto de vista, fiel reflejo del tipo de mujer que era anhelada desde las filas anarquistas. Una construcción de un sujeto femenino en simbiosis entre el romanticismo y la práctica revolucionaria.

En aquel entonces se luchaba en todos los rincones del mundo.

Un alma gemela a la tuya, en Chicago, elevaba el más bello monumento del heroísmo de la juventud femenina. ¿'Te acuerdas de Aurora D’ Ángelo?

Ella era hermosa como tú. Ella era generosa como tú.

Ella era desprejuiciada como tú, joh bella hija de la anarquía!

¡Oh dulce compañera mía!

¡Oh, mi gran amor! ${ }^{74}$

\section{BIBLIOGRAFÍA}

\section{Libros}

\footnotetext{
${ }^{74}$ Carta de Severino Di Giovanni a su amada América Scarfó en Osvaldo Bayer, Severino Di Giovanni. El idealista de la violencia, (Buenos Aires, Argentina: Editorial Planeta,1998) 74
} 
- Antivilo, Julia y Vitale, Luis. Belén de Sárraga: Precursora del feminismo hispanoamericano. Santiago: CESOC, 2000.

- Bakunin, Mijail. Dios y el Estado. Buenos Aires: Ediciones Terramar, 2008

- _ Estatismo y anarquía. Buenos Aires: Anarres, 2007

- Barrancos, Dora. Anarquismo, Educación y costumbres en la Argentina de principios de siglo. Buenos Aires: Editorial Contrapunto, 1990.

- Cappelletti, Ángel. El anarquismo en América Latina. Caracas: Biblioteca Ayacucho, 1990.

2001

La ideología anarquista. Santiago: Ediciones Espíritu Libertario

- Goldman, Emma. La palabra como arma. La Plata: Terramar, 2010.

- Grez, Sergio. De la "regeneración del pueblo" a la huelga general. Génesis y evolución histórica del movimiento popular en Chile (1810-1890). Santiago: DIBAM, 1997.

- L Los Anarquistas y el movimiento obrero: la Alborada de la Idea en Chile, 1893-1915. Santiago: LOM Ediciones, 2007.

- Horowitz, Irving. Los anarquistas. Madrid: Alianza editorial, 1982.

- Kant, Immanuel. ¿Qué es la Ilustración? En Filosofía de la Historia. Buenos Aires: Editorial Nova, 1998

- KROPOTKIN, Piotr. El apoyo mutuo. Buenos Aires: Anarres, 2006

- _ El Estado. Buenos Aires: Terramar, 2010

- L La conquista del pan. Buenos Aires: Anarres, 2005

- Lagos, Manuel. Los Subversivos Las maquinaciones del poder. "República" de Chile, 1920. Santiago: Editorial Quimantú, 2012.

- Montenegro, Walter. Introducción a las doctrinas políticas. Ciudad de México: F.C.E, 1983.

- Ortíz, Oscar. Crónica Anarquista de la subversión olvidada. Santiago: Editorial La Simiente, 2008

- Palomera, Adriana y PINTO, Alejandra. Mujeres en prensa anarquista en Chile, (18911931). Santiago: Ediciones Espíritu Libertario, 2006.

- Proudhon, Pierre-Joseph. El principio federativo. Buenos Aires: Anarres, 2008.

- Salazar, Gabriel y PINTO, Julio. Historia contemporánea de Chile, Tomo I y II Santiago: LOM ediciones, 1999.

- Salazar, Gabriel. Labradores peones y proletarios. Formación y crisis de la sociedad popular chilena del Siglo XIX. Santiago: LOM ediciones, 2000.

- Suriano, Juan. Anarquistas. Cultura y política libertaria en Buenos Aires (1890-1910). Buenos Aires: Ediciones Manantial, 2001

- Woodcock, George. El Anarquismo. Historia de las ideas y movimientos libertarios. Barcelona: Editorial Ariel, 1979.

\section{Artículos:}

- Agliati, Carola y Montero, Claudia. Explorando un espacio desconocido: prensa de mujeres en Chile. 1900-1920, Revista Cyber Humanitatis, invierno 2001, №19. 
- Bacci, Claudia. Feroces de lengua y pluma. Sobre algunas escrituras de mujeres anarquistas. Políticas de la Memoria, Verano 2006-2007, No 6-7.

- Bakunin, Mijail. Circular a mis amigos de Italia (1871). En VELASCO, Demetrio. Ética y poder político en M. Bakunin. Bilbao: Universidad de Deusto, 2008.

$\bullet$

Escritos de filosofía política. Tomo II [en línea]. 11 de noviembre 1874, p. 64 [fecha de consulta: 19 de enero, 2015]. Disponible en: https://es.scribd.com/doc/226103121/Mikhail-Bakunin-Escritos-de-Filosofia-Politica-IIpdf

Catecismo revolucionario. 1864-1867. En BERNARD, Thomas. Ni Dios ni amo: cita de los anarquistas [en línea]. Ciudad de México: Editorial Extemporáneos, 1970 [fecha de consulta 3 enero, 2015]. Disponible en http://nidiosniamocitasanarquistas.blogspot.com/

$\bullet$ [fecha de consulta: 15 enero, 2015]. Disponible en: http://sovmadrid.cnt.es/textos/Mijail\%20Bakunin\%20\%20Federalismo,\%20Socialismo\% 20y\%20Antiteologismo.pdf

- Belluci, Mabel. Anarquismo, sexualidad y emancipación femenina. Argentina alrededor del 900. Revista Nueva Sociedad, septiembre-octubre 1990, №109.

De la pluma a la imprenta. En FLETCHER, Lea. Mujeres y cultura en la Argentina del siglo XIX. Buenos Aires: Feminaria, 1994.

- Fernández, Laura. Queremos emanciparnos: anarquismo y mujer en Buenos Aires de fines del XIX. Revista Izquierdas año 2010, Nº6

- Goldman, Emma. Anarquismo: lo que significa realmente [en línea]. Publicada por vez primera: En inglés en los EE.UU., en Anarchism and Other Essays (1910).Traducción al castellano: Por Sofía Bustamante y revisado por Mateu Llas en base a la tercera edición revisada de 1917, New York: Mother Earth Publishing Association. [fecha de consulta: 5 de enero, 2015]. Disponible en: Wikisource; descargado diciembre de 2009. En http://www.marxists.org/espanol/goldman/1910/002.htm.

V. $1, \mathrm{~N}^{\circ} 1$.

The Tragedy of Woman's Emancipation, Mother Earth, marzo, 1906.

- Kropotkin, Piotr. La Ley y la Autoridad [en línea] agosto, 1913, p. 9 [fecha de consulta: 4 de diciembre, 2014] Disponible en: https://es.scribd.com/doc/172022521/La-Ley-y-LaAutoridad-Piotr-Kropotkin.

- Núñez, Isabel. El sujeto femenino en la pampa salitrera. Diálogo Andino 2008, No 31

- Proudhon, Pierre Joseph. Idea general de la revolución en el siglo XIX. En Bernard, Thomas. Ni Dios ni amo: cita de los anarquistas [en línea]. Ciudad de México: Editorial Extemporáneos, 1970 [fecha de consulta 3 enero, 2015]. Disponible en http://nidiosniamocitasanarquistas.blogspot.com/

La revolución social. En BERNARD, Thomas. Ni Dios ni amo: cita de los anarquistas [en línea]. Ciudad de México: Editorial Extemporáneos, 1970 [fecha de consulta 3 enero, 2015]. Disponible en http://nidiosniamocitasanarquistas.blogspot.com/

- Amor y matrimonio. [en línea]. Publicado en 1858, p. 51 [fecha de consulta: 23 de diciembre, 2014]. Disponible en: http: //www.antorcha. net/ biblioteca_ virtual /filosofia/matrimonio/ indice.html 
- Lagos, Manuel. Viva la Anarquía: Sociabilidad, vida y prácticas culturales anarquistas, Santiago-Valparaíso, 1890-1927. Tesis para optar al Grado de Magíster en Historia. Santiago, USACH. 2009.

- Saavedra, Mario. Los wobblies criollos: Fundación e ideología en la Región chilena de la Industrial Workers of theWorld IWW: 1919-1927. Tesis para optar al grado de licenciado en historia y ciencias sociales. Santiago, ARCIS, 2008.

\section{Periódicos:}

Chile:

- $\quad$ El Rebelde 1898-1899

- La Luz 1902.

- El Martillo

- La Batalla 1913

- Mar y Tierra.

- Verba Roja 1919-1927

- Acción Directa 1921-1923

- El Ácrata 1900-1901

- La Revuelta 1903

- La Voz del Marino 1917.

- La Agitación 1902-1905

- Obrero Panadero 1921.

Argentina:

- Suplementos de La Protesta,

- Estudios,

- Martín Fierro,

- Germen,

- El Azote,

- Ciencia Social,

- La voz de los tiempos,

- Palotes,

- Germen,

- La Campana,

- La voz de los Tiempos

- La voz de la Mujer

Recibido: 15 marzo 2015 Aceptado: 28 mayo 2015 